\title{
Diagnosis and susceptibility testing of methicillin-resistant Staphylococcus aureus in Latin America
}

\begin{abstract}
Strategies to monitor and control the spread of methicillin-resistant Staphylococcus aureus (MRSA) infections are dependent on accurate and timely diagnosis of MRSA in both hospital and community settings. In Latin America, significant diversity in diagnostic and susceptibility testing procedures exists at the regional, national and local levels. Various tests for S. aureus and MRSA are available in clinical settings, but the application of these techniques differs between and within countries, and quality control measures are not uniformly applied to verify diagnoses.

To optimize the diagnosis of MRSA infections across Latin America, a more consistent approach is required. This may include: adoption and appropriate adaption of specific guidelines for MRSA testing, depending on local resources; establishment of a coordinated system for quality control; regional access to central reference facilities; education of medical and healthcare professionals in best practices; and development of systems to evaluate the implementation of guidelines and best practices.
\end{abstract}

Keywords: MRSA, diagnosis, susceptibility testing, Latin America.

\section{INTRODUCTION}

Methicillin-resistant Staphylococcus aureus (MRSA) is an important cause of infections globally and a growing problem across Latin America. ${ }^{1-3}$ Epidemiologic studies in the region have charted a significant rise in MRSA infections both in hospital and community settings. ${ }^{1}$ A key step in the successful treatment of these infections is early and accurate diagnosis.

In clinical settings, diagnosis is based on a combination of epidemiologic information, clinical symptoms and characterization of the infecting MRSA strain. The Monitoring/Surveillance Network for Resistance to Antibiotics, set up with the support of the Pan-American Health Organization (PAHO), provides epidemiologic information on bacterial resistance across Latin America. In some countries, including Argentina, Chile, Ecuador, Uruguay and Venezuela, an organized quality control system is present to support local surveillance, but in others, the capacity for microbiologic diagnosis is limited to a few large university hospitals in the major cities, and limited data, especially regarding community-acquired MRSA, are available in these regions.

Various international guidelines are available that provide recommendations for best practices in MRSA diagnosis and treatment. However, adoption of these recommendations can be sporadic, especially at regional levels where resources may be a significant limiting factor. Most guidelines provide a range of options for MRSA diagnosis that can be adapted for different regional requirements. However, it may not always be clear which tests are appropriate and sufficient in specific circumstances. Additional guidance is therefore required to establish consistency of approach across the region.

\section{GUIDELINES FOR DIAGNOSIS OF MRSA}

Guideline documents have been published in a number of countries outlining recommended protocols and procedures for the identification of MRSA (Table 1 ${ }^{4-9}$ ).

The Clinical and Laboratory Standards Institute (CLSI; formerly the National Committee on
Authors

Jeannete Zurita ${ }^{1}$ Carlos Mejía ${ }^{2}$

Manuel GuzmánBlanco $^{3}$

on behalf of the Latin

American Working

Group on Gram

Positive Resistance.

${ }^{1}$ Hospital Vozandes, Quito, Ecuador.

${ }^{2}$ Hospital Roosevelt, Guatemala City, Guatemala.

${ }^{3}$ Centro Médico de

Caracas, Caracas,

Venezuela.
Correspondence to: Jeannete Zurita Directora del Servicio de Microbiología y Tuberculosis Hospital Vozandes Villalengua Oe2-37 Quito, Ecuador Phone:

+593-2-2262142 Fax:

+593-2-2269234

E-mail: jzurita@hcjb. org.ec 
Table 1. Guidelines for diagnosis of MRSA ${ }^{4-9}$

\begin{tabular}{l|l}
\hline Source & Guidelines \\
\hline Clinical and Laboratory Standards Institute (CLSI) & $\begin{array}{l}\text { Performance Standards for Antimicrobial Susceptibility Testing } \\
\text { Surveillance for Methicillin-Resistant Staphylococcus } \\
\text { aureus: Principles, Practices, and Challenges }\end{array}$ \\
\hline European Antimicrobial Resistance Surveillance System (EARSS) & $\begin{array}{l}\text { New and updated protocols for antimicrobial susceptibility } \\
\text { testing of pathogens under EARSS surveillance 2005 }\end{array}$ \\
\hline $\begin{array}{l}\text { Sociedad Española de Infectologia y } \\
\text { Microbiologia Clinica (SEIMC) }\end{array}$ & Protocolos de diagnostico en Microbiologia $^{7}$ \\
\hline $\begin{array}{l}\text { British Society for Antimicrobial Chemotherapy (BSAC) } \\
\text { Joint Working Party of the British Society for Antimicrobial } \\
\text { Chemotherapy, the Hospital Infection Society and the } \\
\text { Infection Control Nurses Association (BSAC/HIS/ICNA) }\end{array}$ & $\begin{array}{l}\text { GSAC standardized disc susceptibility testing method (version 7) } \\
\text { of methicillin-resistant Staphylococcus aureus }\end{array}$ \\
\hline
\end{tabular}

Clinical Laboratory Standards, NCCLS) in the USA has developed a range of best practice documents covering all aspects of microbiologic testing, including recent publications entitled 'Performance Standards for Antimicrobial Susceptibility Test-

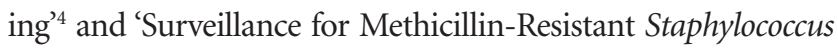
aureus: Principles, Practices, and Challenges.'

The European Antimicrobial Resistance Surveillance System (EARSS), funded by the European Commission, provides a comprehensive surveillance and information system on the spread of antimicrobial resistance in Europe. EARSS has published protocols for diagnostic testing of various organisms with antibiotic resistance traits, including MRSA, VISA and VRSA. ${ }^{6,10}$ Similarly, the Sociedad Española de Infectologia y Microbiologia Clinica (SEIMC), based in Spain, has published recommendations for the identification of various bacterial strains with antimicrobial resistance, including MRSA. ${ }^{7}$

In the UK, the British Society for Antimicrobial Chemotherapy (BSAC) published their first guidelines on microbial sensitivity testing in 1991, including minimum inhibitory concentration (MIC) breakpoints for clinically relevant bacteria, and more recently provided standardized methods for disc susceptibility testing for a range of organisms, including MRSA. ${ }^{8}$ A Joint Working Party of the BSAC, the Hospital Infection Society (HIS) and the Infection Control Nurses Association (ICNA) recently published evidence-based guidelines on the laboratory diagnosis of MRSA. ${ }^{9}$ These guidelines include recommendations on the identification of MRSA and methods of susceptibility testing and screening.

Since the various guidelines differ in their scope and detail, and generally do not apply specifically to infections in Latin America, infection control teams are advised to choose guidelines to follow and to adapt them to their local situation, considering such factors as epidemiology, available antibiotics and resources, likely sources of infection, and risk factors associated with their specific patient population and environment. The CLSI guidelines are the guidelines of choice in most Latin American countries. Evaluation of the implementation of guidelines is also important, as is education of healthcare workers, in order to ensure that consistent best practices are maintained.

\section{IDENTIFICATION OF S. AUREUS}

S. aureus causes a wide range of clinical infections, resulting in direct invasion of bacteria into different organs and consequent tissue damage. The clinical manifestations of infection result from the release of various toxins, either locally or systemically, and include a range of diseases dependent on the location of the infection (Table 2).

For localized infections, a clinical diagnosis is often sufficient without the need for analysis of cultures. However, for systemic infections, proper and prompt detection of $S$. aureus strains and their susceptibility to different antibiotics is of paramount importance in order for healthcare workers to provide appropriate treatment, and to initiate relevant control measures.

Initial, rapid assessment of clinical samples is typically achieved using conventional microscopy, by which staphylococci appear as rounded, Gram-positive cocci growing in clusters. It is important to distinguish S. aureus isolates from other staphylococcal species, such as coagulase-negative staphylococci (CoNS), and various tests are available to achieve this (Table 3). While several of these tests can be used interchangeably under appropriate circumstances, the relative benefits and limitations of each should be understood by microbiologists and healthcare professionals in order that appropriate conclusions can be drawn.

A number of factors influence the choice of $S$. aureus identification tests employed in a given situation, including cost, speed of result, facilities available, sensitivity and specificity. The joint BSAC/HIS/ICNA guidelines ${ }^{9}$ recommended that a tube coagulase or latex agglutination test 
Table 2. Clinical manifestations of S. aureus infection

\begin{tabular}{l|l}
\hline Source of infection & \multicolumn{2}{l}{ Disease } \\
\hline Skin and soft tissue & $\begin{array}{l}\text { Impetigo, boils, carbuncles, abscesses, cellulitis, fasciitis, } \\
\text { pyomyositis, surgical and traumatic wound infections }\end{array}$ \\
\hline Foreign body-associated & Intravascular catheter, urinary catheter \\
\hline Intravascular & Bacteraemia, sepsis, septic thrombophlebitis, infective carditis \\
\hline Bone and joints & Septic osteomyelitis, septic arthritis \\
\hline Respiratory & Pneumonia, empyema, sinusitis, otitis media \\
\hline Other invasive infections & Meningitis, surgical space infection \\
\hline Toxin-mediated disease & $\begin{array}{l}\text { Staphylococcal toxic shock, food poisoning, staphylococcal } \\
\text { scalded skin syndrome, bullous impetigo, necrotizing pneumonia, } \\
\text { necrotizing osteomyelitis }\end{array}$ \\
\hline
\end{tabular}

Table 3. Methods for identification of S. aureus isolates

\begin{tabular}{|c|c|c|}
\hline Principle & Method & Considerations \\
\hline \multicolumn{3}{|l|}{ Test: Coagulase } \\
\hline $\begin{array}{l}\text { Coagulase produced by certain Gram- } \\
\text { positive cocci, including } S \text {. aureus either } \\
\text { in bound form (attached to the bacterial } \\
\text { cell wall) or as free enzyme, converts } \\
\text { fibrinogen to insoluble fibrin in the } \\
\text { presence of plasma, resulting in clotting }\end{array}$ & $\begin{array}{l}\text { Tube test } \\
\text { Detects free coagulase } \\
\text { Bacterial suspension added to diluted } \\
\text { rabbit plasma and incubated at } 37^{\circ} \mathrm{C} \\
\text { Free coagulase causes plasma to } \\
\text { clot into a gel, usually within } 4 \mathrm{~h}\end{array}$ & $\begin{array}{l}\text { Tube test } \\
\text { Some staphylococcus species } \\
\text { not commonly found in human } \\
\text { isolates (e.g. S. schleiferi and } S \text {. } \\
\text { intermedius) may test positive } \\
\text { Occasionally, rare } S \text {. aureus } \\
\text { may test negative } \\
\text { Some strains require up to } 24 \text { h incubation } \\
\text { Tests should not be incubated beyond } 24 \mathrm{~h}\end{array}$ \\
\hline $\begin{array}{l}\text { Presence of coagulase distinguishes } \\
\text { S. aureus from coagulase-negative } \\
\text { staphylococci (CoNS) }\end{array}$ & $\begin{array}{l}\text { Slide test } \\
\text { Detects cell-bound coagulase } \\
\text { Bacterial suspension mixed } \\
\text { with plasma on a slide } \\
\text { Presence of bound coagulase causes } \\
\text { cocci to clump together rapidly }(5-10 \mathrm{~s})\end{array}$ & $\begin{array}{l}\text { Slide test } \\
\text { Rapid result } \\
\text { 10-15\% of S. aureus strains test negative } \\
\text { Some other staphylococcus species test } \\
\text { positive (e.g. S. schleiferi, S. lugdunensis) }\end{array}$ \\
\hline \multicolumn{3}{|l|}{ Test: Latex agglutination } \\
\hline $\begin{array}{l}\text { Proteins on the surface of } S \text {. aureus (e.g. } \\
\text { protein A, clumping factor group-specific } \\
\text { antigens, capsular polysaccharides), } \\
\text { are recognized by specific latex } \\
\text { spheres, resulting in aggregation }\end{array}$ & $\begin{array}{l}\text { S. aureus bacterial suspension } \\
\text { mixed with specific latex spheres } \\
\text { Aggregation results in a clearing } \\
\text { of background media }\end{array}$ & $\begin{array}{l}\text { Latex agglutination kits specific for } \\
\text { S. aureus available commercially } \\
\text { (e.g. Staphaurex, Staphaurex Plus; } \\
\text { Wellcome Diagnostics, UK) } \\
\text { Detect both MSSA and MRSA } \\
\text { Sensitivity > 98\% for all S. aureus strains } \\
\text { Cheap, rapid test } \\
\text { Some other staphylococcus } \\
\text { species may test positive (e.g. S. } \\
\text { schleiferi, S. lugdunensis) }\end{array}$ \\
\hline \multicolumn{3}{|l|}{ Test: Catalase } \\
\hline $\begin{array}{l}\text { S. aureus produce abundant catalase, } \\
\text { which can interact with hydrogen } \\
\text { peroxide to produce oxygen }\end{array}$ & $\begin{array}{l}3 \% \text { hydrogen peroxide added } \\
\text { to colonies on agar plate } \\
\text { Catalase-positive colonies produce } \\
\text { oxygen and bubble almost immediately }\end{array}$ & $\begin{array}{l}\text { Cheap, rapid result } \\
\text { Distinguishes catalase-producing } \\
\text { cocci (e.g. staphylococci) from non- } \\
\text { producers (e.g. streptococci) } \\
\text { Cannot be performed on blood agar } \\
\text { because blood contains catalase }\end{array}$ \\
\hline
\end{tabular}




\section{Test: Mannitol salt agar (MSA)}

S. aureus strains grow well in high salt and are able to ferment mannito to produce acid, which can be detected using a $\mathrm{pH}$ indicator
Bacteria plated onto MSA consisting of mannitol, 7.5-10\% salt and the $\mathrm{pH}$ indicator phenol red

Pathogenic staphylococci, such as $S$. aureus, grow well in high salt and turn MSA yellow through the release of acid
Usually detects MRSA and MSSA

MSA can be supplemented with other antimicrobials, including cefoxitin, for MRSA screening

\section{Test: Polymyxin B and novobiocin susceptibility}

\begin{tabular}{|c|c|c|}
\hline $\begin{array}{l}\text { Polymyxin B is a cationic detergent } \\
\text { antibiotic-specific for Gram-negative bacilli }\end{array}$ & $\begin{array}{l}\text { Discs of polymyxin B (10 U) } \\
\text { added to agar plate } \\
\text { S. aureus are resistant to polymyxin B }\end{array}$ & \multirow[t]{2}{*}{$\begin{array}{l}\text { Polymyxin B and novobiocin discs are } \\
\text { relatively cheap and easy to use } \\
\text { They should be used as part of a series } \\
\text { of diagnostic tests for } S \text {. aureus }\end{array}$} \\
\hline $\begin{array}{l}\text { Novobiocin is an amino-coumarin } \\
\text { antibiotic which can be used to } \\
\text { differentiate } S \text {. aureus from some CoNS }\end{array}$ & $\begin{array}{l}\text { Discs of novobiocin }(5 \mu \mathrm{g}) \\
\text { added to agar plate } \\
\text { S. aureus and some CoNS (e.g. S. } \\
\text { epidermis) are sensitive to novobiocin, } \\
\text { whereas most other CoNS (e.g. S. } \\
\text { saprophyticus) are resistant }\end{array}$ & \\
\hline \multicolumn{3}{|l|}{ Test: DNase and heat-stable nucleases } \\
\hline $\begin{array}{l}\text { Identification of } S \text {. aureus based on } \\
\text { detection of specific DNase and heat-stable } \\
\text { nucleases common to } S \text {. aureus strains }\end{array}$ & $\begin{array}{l}\text { Methods include anti-nuclease test to } \\
\text { measure antibody to nucleases common to } \\
\text { all strains of } S \text {. aureus, and metachromatic } \\
\text { agar diffusion for heat-stable nucleases }\end{array}$ & $\begin{array}{l}\text { Some rare CoNS can be positive } \\
\text { in heat-stable nuclease tests } \\
\text { S. aureus can be detected on } \\
\text { deoxyribonuclease (DNase) } \\
\text { plates used to screen isolates } \\
\text { Since various amounts of DNase are } \\
\text { produced by CoNS, positives should } \\
\text { be confirmed with an additional test }\end{array}$ \\
\hline \multicolumn{3}{|l|}{ Test: Automated methods } \\
\hline $\begin{array}{l}\text { Automated systems employ a battery of } \\
\text { tests to achieve } S \text {. aureus identification }\end{array}$ & $\begin{array}{l}\text { Commercial systems include: } \\
\text { VITEK/VITEK2 (bioMerieux }{ }^{\circledR} \text { ) } \\
\text { Phoenix (BD Biosciences) } \\
\text { Microscan (Dade Behring) }\end{array}$ & $\begin{array}{l}\text { Convenient and reliable for } S \text {. aureus } \\
\text { Resource issues limit use in } \\
\text { smaller laboratories }\end{array}$ \\
\hline \multicolumn{3}{|l|}{ Test: Molecular methods } \\
\hline $\begin{array}{l}\text { S. aureus contain a number of genes } \\
\text { that allow them to be distinguished } \\
\text { from other staphylococcal species }\end{array}$ & $\begin{array}{l}\text { Methods include PCR (simple, multiplex } \\
\text { and real-time), DNA sequencing, and } \\
\text { hybridization-based techniques } \\
\text { Species-specific genes commonly used } \\
\text { include nuclease (nuc), coagulase (coa), } \\
\text { protein A (spa), femA and femB, Sa442, } \\
\text { and } S \text {. aureus specific 16S rRNA }\end{array}$ & $\begin{array}{l}\text { Robust and simple to perform } \\
\text { Many local laboratories do not have } \\
\text { facilities for molecular approaches }\end{array}$ \\
\hline
\end{tabular}

should be used for routine identification of $S$. aureus or for confirmation after DNase tests, or after negative results in a slide coagulase test. Although the readout from the slide test is much quicker than for the tube test (15s vs. 4-24 h), the former has a higher false-negative rate $(\sim 15 \%)$. Consequently, the tube test is considered more definitive, and is the preferred coagulase test for identification of S. aureus.

Under circumstances where clinicians require a rapid assessment of MRSA, a slide coagulase test may be confirmed by latex agglutination, automated approaches or molecular tests. An international multicenter study, in which various commercial agglutination kits for identification of $S$. aureus were assessed using 892 staphylococcal isolates, found reliable detection of S. aureus (> 98\% sensitivity and > 98\% selectivity for Slidex Staph Plus). ${ }^{11}$ Automated tests provide a similar level of accuracy for identification of S. aureus and are used across Latin America, but these may not be available in smaller local centers.

More sophisticated approaches to speciation of staphylococci are available that can provide identification of most species, but tend to involve a greater battery of tests. In a Brazilian study, Iorio et al..$^{12}$ demonstrated a scheme for the rapid identification of 198 staphylococcal isolates (including 17 of $S$. aureus) using a simplified battery of phenotypic tests. Staphylococci were initially identified using Gram stain, the catalase test, acid production from glucose in Hugh and Leifson's OF base medium, and susceptibility to bacitracin. Nine phenotypic tests were then used to distinguish staphy- 
lococcal species, achieving 98.5\% accuracy across species (100\% for S. aureus) in 72 h. Such schemes may be useful in routine laboratories, and particularly in developing countries where costs and resources are significant issues.

\section{Methicillin sensitivity testing}

There are many options for testing methicillin susceptibility of S. aureus, including disc diffusion, MIC measurements (in broth or by Etest), chromogenic agar, latex agglutination, automated methods, rapid screening methods and molecular approaches (see Table $4^{4,5,8,9,13-20}$ for details).

For media-based methods, test conditions such as media type, incubation times and temperature, play an important role in determining the outcome of methicillin sensitivity tests, as reflected in many of the published guidelines, and these factors should be considered carefully when designing appropriate tests. The BSAC recommends Columbia or $\mathrm{Mu}-$ eller Hinton agar supplemented with $\mathrm{NaCl}(2 \%)$ for dilution and disc diffusion methods, ${ }^{4,8}$ and addition of up to $5 \% \mathrm{NaCl}$ to media has been shown to improve detection of resistance for most strains. ${ }^{21,22}$ Typically, methicillin resistance is detected more reliably at lower temperatures $\left(30-35^{\circ} \mathrm{C}\right),{ }^{23-25} \mathrm{al}-$ though some rare strains may grow slowly at $30^{\circ} \mathrm{C}$ when $5 \%$ $\mathrm{NaCl}$ is present. Both the CLSI and BSAC recommend that

Table 4. MRSA susceptibility testing ${ }^{4,5,8,9,13-20}$

\begin{tabular}{|c|c|c|}
\hline Principle & Recommended method & Considerations \\
\hline \multicolumn{3}{|l|}{ Test: Disc diffusion (Kirby-Bauer) } \\
\hline $\begin{array}{l}\text { Discs containing antimicrobial agent } \\
\text { placed on the surface of agar plate } \\
\text { inoculated with bacterial suspension, and } \\
\text { zone of inhibition assessed around colonies }\end{array}$ & $\begin{array}{l}\text { Disc diffusion }{ }^{4,8,9} \\
2 \% \mathrm{NaCl} \text { in } \mathrm{MH} \text { or Columbia agar } \\
\text { Incubation } 30-35{ }^{\circ} \mathrm{C} \text { for } \geq 24 \mathrm{~h} \\
\text { Cefoxitin discs are more reliable than } \\
\text { oxacillin discs. }{ }^{13,14,26,27} \text { Zone for oxacillin or } \\
\text { cefoxitin should be read by holding plate } \\
\text { up to light source }\end{array}$ & $\begin{array}{l}\text { Some strains show heteroresistance, which } \\
\text { is apparent as an inner zone within a } \\
\text { larger zone of inhibition } \\
\text { On oxacillin discs, some hyper-producers } \\
\text { of penicillinase give no zone of inhibition } \\
\text { and will be incorrectly reported as MRSA }\end{array}$ \\
\hline \multicolumn{3}{|c|}{ Test: MIC determinations following antibiotic dilution in broth or agar } \\
\hline $\begin{array}{l}\text { Growth in different dilutions of } \\
\text { antimicrobial agent in broth or agar to } \\
\text { reveal MIC }\end{array}$ & $\begin{array}{l}\text { Broth } \\
2 \% \mathrm{NaCl} \text { in } \mathrm{MH} \text { broth }+ \text { oxacillin or } \\
\text { cefoxitin } \\
\text { Inoculum of } 5 \times 10^{5} \mathrm{cfu} / \mathrm{mL} \\
\text { Incubation } 33-35^{\circ} \mathrm{C} \text { for } 24 \mathrm{~h} \\
\text { Agar, } 4,9 \\
\text { Tests on } \mathrm{MH} \text { or Columbia agar with } 2 \% \\
\mathrm{NaCl}+\text { oxacillin } \\
\text { Inoculum of } 10^{4} \mathrm{cfu} / \mathrm{mL} \\
\text { Incubation at } 30-35^{\circ} \mathrm{C} \text { for } 24 \mathrm{~h}\end{array}$ & $\begin{array}{l}\text { Relatively cheap } \\
\text { More cumbersome than disc diffusion, } \\
\text { Etest and latex agglutination methods }\end{array}$ \\
\hline \multicolumn{3}{|l|}{ Test: Etest } \\
\hline $\begin{array}{l}\text { Etest }^{\circledR} \text { (bioMerieux), based on plastic strips } \\
\text { containing a predefined gradient of } 15 \\
\text { antibiotic concentrations }\end{array}$ & $\begin{array}{l}\text { Etest }^{15-18} \\
2 \% \mathrm{NaCl} \text { in } \mathrm{MH} \text { agar } \\
\text { Inoculum density equivalent to } 0.5-1.0 \\
\mathrm{McFarland} \text { standard } \\
\text { Incubation at } 35^{\circ} \mathrm{C} \text { for } 24 \mathrm{~h} \\
\text { Strips laid out on agar plate, and growth } \\
\text { assessed along gradient to determine } \mathrm{MIC}\end{array}$ & $\begin{array}{l}\text { Easy to set up } \\
\text { Not widely used in Latin America due to } \\
\text { cost }\end{array}$ \\
\hline \multicolumn{3}{|l|}{ Test: Plate screening } \\
\hline Agar plates for screening & $\begin{array}{l}\text { Plate screening } \\
4 \% \mathrm{NaCl} \text { in } \mathrm{MH} \text { agar }+ \text { oxacillin } \\
6 \mathrm{mg} / \mathrm{L} \\
\text { Inoculum density equivalent to } 0.5 \\
\mathrm{McFarland} \text { standard } \\
\text { Incubation at } \leq 35^{\circ} \mathrm{C} \text { for } 24 \mathrm{~h} \\
>1 \text { colony is indicative of resistance }\end{array}$ & $\begin{array}{l}\text { Cheap, reliable } \\
\text { Recommended for screening and } \\
\text { confirming resistance identified by disc } \\
\text { diffusion }\end{array}$ \\
\hline
\end{tabular}




\begin{tabular}{|c|c|c|}
\hline \multirow[t]{5}{*}{$\begin{array}{l}\text { MRSA strains produce penicillin-binding } \\
\text { protein 2a (PBP2a) }\end{array}$} & $\begin{array}{l}\text { PBP2a extracted from a suspension of } \\
\text { colonies }\end{array}$ & $\begin{array}{l}\text { Rapid, cheap and reliable method for } \\
\text { detection of MRSA }\end{array}$ \\
\hline & Latex particles coated with monoclonal & \\
\hline & $\begin{array}{l}\text { antibodies to PBP2a added to extract } \\
\text { Presence of PBP2a causes particle } \\
\text { agglutination }\end{array}$ & $\begin{array}{l}\text { Isolates producing small amounts of PBP2a } \\
\text { may give weak agglutination reactions, or } \\
\text { agglutinate slowly }\end{array}$ \\
\hline & $\begin{array}{l}\text { Addition of a penicillin may induce } \mathrm{PBP} 2 \mathrm{a} \\
\text { production and give a stronger reaction }\end{array}$ & $\begin{array}{l}\text { Some rare MRSA isolates may test } \\
\text { negative }\end{array}$ \\
\hline & Also available in slide format & $\begin{array}{l}\text { May not be reliable for colonies grown on } \\
\text { media containing } \mathrm{NaCl}\end{array}$ \\
\hline \multicolumn{3}{|l|}{ Test: Chromogenic agar } \\
\hline $\begin{array}{l}\text { Chromogenic agars specific for MRSA, } \\
\text { allowing rapid detection of colonies } \\
\text { through colored reactions }\end{array}$ & $\begin{array}{l}\text { Several commercial agars available, }{ }^{19,20} \\
\text { including: } \\
\text { S. aureus ID (bioMérieux) } \\
\text { CHROMagar MRSA (CHROM agar) } \\
\text { Chromogenic MRSA Agar (Oxoid) }\end{array}$ & $\begin{array}{l}\text { Chromogenic agars can have high } \\
\text { sensitivity for MRSA } \\
\text { (>98\%) } \\
\text { Appropriate for rapid MRSA screening }\end{array}$ \\
\hline \multicolumn{3}{|l|}{ Test: Automated methods } \\
\hline $\begin{array}{l}\text { Automated systems employ a battery of } \\
\text { tests to provide a convenient, and often } \\
\text { rapid, approach to S. aureus and MRSA } \\
\text { identification }\end{array}$ & $\begin{array}{l}\text { Commercial systems } \\
\text { VITEK GPI (bioMerieux }^{\circledast} \text { ) } \\
\text { Phoenix (BD Biosciences) } \\
\text { Microscan (Dade Behring) }\end{array}$ & $\begin{array}{l}\text { Convenient and reliable for } S \text {. aureus } \\
\text { Some false-positives may be identified } \\
\text { These methods can be used for detection of } \\
\text { MRSA, but do not detect VRSA }\end{array}$ \\
\hline \multicolumn{3}{|l|}{ Test: Molecular methods } \\
\hline $\begin{array}{l}\text { MRSA strains possess mecA gene, which } \\
\text { encodes penicillin-binding protein } 2 \mathrm{a} \\
\text { (PBP2a) }\end{array}$ & $\begin{array}{l}\text { Methods include PCR (simple, multiplex } \\
\text { and real-time), DNA sequencing and } \\
\text { hybridization-based techniques } \\
\text { Detection of mecA for methicillin } \\
\text { resistance is combined with species- } \\
\text { specific genes such as nuclease (nuc), } \\
\text { coagulase (coa), protein A (spa), femA and } \\
\text { femB, Sa442, } 16 \mathrm{~S} \text { rRNA fibrinogen-binding } \\
\text { protein genes }\end{array}$ & $\begin{array}{l}\text { Robust and simple to perform } \\
\text { Rapid and unambiguous characterization } \\
\text { of MRSA } \\
\text { Reference method of choice for MRSA } \\
\text { confirmation } \\
\text { May detect occasional susceptible strains } \\
\text { carrying a non-functional or non-expressed } \\
\text { mecA } \\
\text { Resource issues reduce widespread use }\end{array}$ \\
\hline
\end{tabular}

incubations are performed for $24 \mathrm{~h},{ }^{4,8}$ but for some heterogeneous strains, resistant sub-populations may grow more slowly, and incubations of $48 \mathrm{~h}$ may be required to improve detection. Cefoxitin has now taken over as the antibiotic of choice for methicillin sensitivity testing, with methicillin itself no longer produced. Oxacillin remains a second option, but several publications have demonstrated that cefoxitin is more reliable than oxacillin. ${ }^{13,14,26,27}$

In Latin America, the methodology used for identification of MRSA differs between countries. The disc diffusion method, using oxacillin or cefoxitin discs, is popular in some countries, whereas Etest strips are generally considered too expensive for routine use. Confirmation tests, such as the methicillin screen plate test, are not widely used and molecular analysis of MRSA strains is restricted to a few centers in Brazil, Argentina, Chile, Mexico and Colombia. In cases of nosocomial outbreaks, the identity of MRSA strains is usually assumed from the phenotypic pattern of antibiotic resistance. Many laboratories in Latin America use automated methods, and these offer a convenient and, in some cases, rapid approach to identification of MRSA. The VITEK GPI system and more recent VITEK2 (Biomerieux ${ }^{\circledR}$ ), the Microscan ${ }^{\circledR}$ Rapid POS COMBO (Dade/Microscan) and the Phoenix system (BD Biosciences), are all widely used for detection of MRSA, and the Vitek system will also soon include a screening test for vancomycin susceptibility.

The joint BSAC/HIS/ICNA guidelines ${ }^{9}$ recommended that "a standard, recognized method, such as those published by the BSAC or the CLSI, should be used for routine susceptibility testing of S. aureus', but that 'other tests should be considered acceptable if they give equivalent or better performance". Disc diffusion, MIC determination and latex agglutination are all sufficient and affordable methods for routine methicillin sensitivity testing. Latex agglutination to detect penicillin-binding protein 2a (PBP2a) may also be used as a confirmatory method.

Rapid detection of MRSA is especially important in settings where quick preventive or therapeutic measures are 
needed, such as in intensive care units and in some surgical interventions where prosthetic material substitutions are required. Latex agglutination and ChromAgar are reliable methods for detection of MRSA and the results are available more quickly than other methods.

Importantly, consistent protocols should be introduced for all of the above tests where possible, and should be carried out using appropriate susceptible and resistant control strains, such as those outlined in the BSAC and CLSI guidelines. ${ }^{4,8}$ For MIC and disc diffusion studies, reference values for MIC and zone of inhibition are provided in the CLSI guidelines to define susceptibility, intermediate resistance and resistance to specific antimicrobial agents (Table 5). ${ }^{4}$ MRSA should be reported as resistant to all currently-available -lactam agents (penicillins, -lactamase/-lactamase inhibitor combinations, cephems and carbapenems), since activity of -lactam agents against MRSA in in vitro tests does not necessarily translate into clinical efficacy.

\section{DETECTION OF REDUCED SUSCEPTIBILITY TO VANCOMYCIN (VRSA AND VISA)}

MRSA infections are commonly treated with glycopeptide antibiotics such as vancomycin and teicoplanin. However, MRSA isolates with reduced susceptibility or resistance to vancomycin have emerged in recent years, ${ }^{28}$ including in Latin America. ${ }^{29}$ Globally, these isolates have been termed vancomycin-intermediate $S$. aureus (VISA) and vancomycin-resistant $S$. aureus (VRSA) depending on their level of resistance. Although VISA/VRSA strains have not been identified frequently in Latin America, and the incidence does not appear to be increasing, ${ }^{30}$ the potential importance of these organisms is reflected in the inclusion of vancomycin susceptibility testing within guidelines for the diagnosis of MRSA..$^{8-10}$

The current 'gold standard' for the diagnosis of VISA or VRSA is the screen test. Here, plates made up of brainheart infusion agar and $6 \mathrm{mg} / \mathrm{mL}$ vancomycin are spotted with a $10 \mu \mathrm{l}$ inoculum of a 0.5 McFarland bacterial suspension and incubated for $24 \mathrm{~h}$, with the growth of more than one colony signifying a positive result. ${ }^{31}$ S. aureus ATCC 25923 and Enterococcus faecalis ATCC 51299 may be used as negative and positive controls, respectively. Mueller Hinton agar containing vancomycin or teicoplanin may also be used in the screen test, ${ }^{8,9}$ but a longer incubation time $(48 \mathrm{~h})$ is suggested.

Most guidelines recommend MIC methods for confirmation of positive screen test results. ${ }^{9} 10$ However, care should be taken in choosing appropriate tests for VISA and VRSA, since not all methods are appropriate for both

Table 5. CLSI-recommended reference MIC and zone diameter breakpoints for S. aureus ${ }^{4}$

\begin{tabular}{|c|c|c|c|c|c|c|c|}
\hline \multirow[t]{2}{*}{ Antimicrobial agent } & \multirow{2}{*}{$\begin{array}{c}\text { Disc content } \\
(\mu \mathrm{g})^{*}\end{array}$} & \multicolumn{3}{|c|}{$\begin{array}{l}\text { Zone diameter breakpoints } \\
\text { (nearest } \mathrm{mm})^{*}\end{array}$} & \multicolumn{3}{|c|}{ MIC standard $(\mu \mathrm{g} / \mathrm{mL})^{*}$} \\
\hline & & $\mathrm{S}$ & I & $\mathrm{R}$ & $\mathrm{S}$ & I & $\mathrm{R}$ \\
\hline Methicillin & 5 & $\geq 14$ & $10-13$ & $\leq 9$ & $\leq 8$ & - & $\geq 16$ \\
\hline Oxacillin & 1 & $\geq 13$ & $11-12$ & $\leq 10$ & $\leq 2$ & - & $\geq 4$ \\
\hline Cefoxitin & 30 & $\geq 22$ & - & $\leq 21$ & $\leq 4$ & - & $\geq 8$ \\
\hline Vancomycin & - & - & - & - & $\leq 2$ & $4-8$ & $\geq 16$ \\
\hline Teicoplanin & 30 & $\geq 14$ & $11-13$ & $\leq 10$ & $\leq 8$ & 16 & $\geq 32$ \\
\hline Clindamycin & 2 & $\geq 21$ & $15-20$ & $\leq 14$ & $\leq 0.5$ & $1-2$ & $\geq 4$ \\
\hline Daptomycin & - & - & - & - & $\leq 1$ & - & - \\
\hline Linezolid & 30 & $\geq 21$ & - & - & $\leq 4$ & - & - \\
\hline Rifampin & 5 & $\geq 20$ & $17-19$ & $\leq 16$ & $\leq 1$ & 2 & $\geq 4$ \\
\hline Quinupristin-dalfopristin & 15 & $\geq 19$ & $16-18$ & $\leq 15$ & $\leq 1$ & 2 & $\geq 4$ \\
\hline $\begin{array}{l}\text { Trimethoprim- } \\
\text { sulfamethoxazole }\end{array}$ & $1.25 / 23.75$ & $\geq 16$ & $11-15$ & $\leq 10$ & $\leq 2 / 38$ & - & $\geq 4 / 76$ \\
\hline
\end{tabular}

S - Susceptible; I - Intermediate resistance; R - Resistant

*Reproduced, with permission, from CLSI publication M100-S19, Performance Standards for Antimicrobial

Susceptibility Testing, Table 2C. Copies of the current edition may be obtained from Clinical and Laboratory Standards

Institute, 940 West Valley Road, Suite 1400, Wayne, Pennsylvania 19087-1898, USA. www.clsi.org 
strains (Table 6). VISA and VRSA, for example, are not reliably detected using automated methods, ${ }^{31,32}$ whereas disc diffusion is inappropriate for VISA, but can be used for VRSA. Generally, a non-automated MIC method (e.g. broth dilution, agar dilution or Etest) with a 24-hour incubation is appropriate. ${ }^{8,10}$ Strains with a MIC of $\leq 2 \mu \mathrm{g} /$ $\mathrm{mL}$ are considered susceptible to vancomycin (Table 5), although increasing vancomycin MICs within this 'susceptible' range have been linked to an increased risk of clinical failure. ${ }^{33}$ VISA with heterogeneous sensitivity to vancomycin (h-VISA) should be confirmed by a population analysis profile (PAP) method, since MICs for these strains may be similar to those for susceptible strains. ${ }^{9}$

It has been proven that h-VISA significantly complicates the treatment of bacteremia patients and that it frequently not identified by clinical laboratories. The best detection method for h-VISA is the measurement of the area under the curve (AUC) from a PAP test, however it is very labour-intensive, costly and is not appropriate in a clinical setting. There are currently three reasonable alternatives to PAP that are highly sensitive and specific and that must be used in all MRSA isolates with a vancomycin MIC of $1-2 \mu \mathrm{g} / \mathrm{mL}$.

1) "New strip" Etest detection method for resistance

to glycopeptides (vancomycin, 32-0.5 $\mu \mathrm{g} / \mathrm{mL}$; teicoplanin, 32-0.5 $\mu \mathrm{g} / \mathrm{mL}$; bioMérieux $\mathrm{AB})^{34}$

2) Mueller-Hinton agar supplemented

with $5 \mu \mathrm{g} / \mathrm{mL}$ teicoplanin

3) Plates made up of brain heart infusion agar

supplemented with $6 \mu \mathrm{g} / \mathrm{mL}$ vancomycin,

as described in the literature $\mathrm{e}^{28,35}$

Following positive tests for VISA or VRSA, samples should be forwarded to a reference laboratory for population analysis using appropriate control strains (for example, ATCC 700698, ATCC700699 and Oxford strain, or an alternative control ${ }^{10}$ ). Organisms that can be used as controls for sensitivity testing, for the evaluation of low levels of glycopeptide resistance (glycopeptide intermediate S. aureus

Table 6. VISA and VRSA detection

\begin{tabular}{l|c|c}
\hline \multirow{2}{*}{ Test } & \multicolumn{2}{c}{ Suitable for: } \\
\cline { 2 - 3 } Screen test & Yes & Yes \\
\hline Broth dilution & Yes & Yes \\
\hline Agar dilution & Yes & Yes \\
\hline Etest & Yes & Yes \\
\hline Diffusion method & No & $\begin{array}{c}\text { Yes } \\
\text { (but results may be } \\
\text { equivocal) }\end{array}$ \\
\hline Automated methods & No & No \\
\hline
\end{tabular}

[GISA]) and heterogeneous glycopeptide resistance (heterogeneous GISA [h-GISA]) are: S. aureus ATCC 29213, ATCC 700698 (Mu3; h-GISA) and ATCC 700699 (Mu50; GISA).

The heteroresistance phenomenon has been in MRSA strains which, despite having a vancomycin MIC below that of the breakpoint of susceptible strains, had subpopulations growing in the presence of $4-8 \mu \mathrm{g} / \mathrm{mL}$ of vancomycin. ${ }^{28,36}$ Since their description, these strains have been called vancomycin-heteroresistant and have been detected in several countries, ${ }^{37,38}$ including some countries in Latin America. In a study carried out in Venezuela, Colombia, Ecuador and Peru, Reyes et al. described nine strains of h-VISA in 1,570 S. aureus $(0.57 \%) .{ }^{39}$ This heterogeneity in vancomycin resistance is similar to that described for methicillin in MRSA, where only $1 \times 10^{-6}$ bacteria express this characteristic.

Vancomycin heteroresistance has been considered as a potential cause of therapeutic failure. ${ }^{38}$ However, to know the real incidence and importance of this strain type, it is necessary to establish a reliable and reproducible detection method. Some authors suggest that current vancomycin heteroresistance detection methods induce, rather than detect, resistance to vancomycin, and thus it will be impossible to establish its clinical relevance until we better understand the control mechanisms of vancomycin resistance. ${ }^{40,41}$

Susceptibility testing should also be performed for erythromycin, clindamycin (including detection of the inducible mechanism in erythromycin resistant strains), daptomycin, linezolid, rifampin, quinupristin/dalfopristin and trimethoprim/sulfamethoxasole. These tests can be performed in-house if appropriate facilities are available or, more frequently, in a reference laboratory. It is recommended that probable isolates of VISA and VRSA are sent to a reference laboratory as quickly as possible, even if there is a capability to test additional agents in-house, in order to facilitate organism confirmation and enhance infection control efforts.

\section{IMPLICATIONS FOR THE REGION}

The growing incidence and awareness of MRSA across Latin America has been met by an extensive effort towards early diagnosis, appropriate intervention and widespread surveillance. As would be expected from a region with such diversity in resources, a wide variety of diagnostic tests are used routinely in clinical practice, illustrated in this review, and various quality control measures are applied. As MRSA is likely to be a continuous threat to public health in Latin America for the foreseeable future, it is timely that current processes are reviewed and measures to ensure consistent practices are adopted across the region.

Existing guidelines covering MRSA diagnosis and treatment are thorough, and these should be used as a basis to standardize practices. A tiered set of recommendations may be required to accommodate both well-funded, larger cent- 
ers, and local clinics with limited resources. Also, recommendations may need to be adapted for individual countries based on local resources, epidemiology and specific clinical requirements.

A coordinated system for quality control is a key requirement for successful MRSA diagnosis, and centralized, accessible reference facilities should be developed to support local centers. Collaboration within individual countries and across the region is important in this regard.

Education is a key factor in providing consistency of approach. Microbiology laboratories should participate in the education of medical and healthcare students and workers to perform procedures appropriately, and regional support networks should be set up to provide longer-term support and to facilitate the introduction of new techniques. Finally, systems to evaluate the implementation of guidelines should be introduced in order to ensure that consistent and best practices are adopted and maintained across the region.

While these recommendations are unlikely to halt the spread of antibiotic resistant $S$. aureus strains across Latin America, they should assist healthcare workers in achieving the most appropriate balance between the management of local resources and the provision of high quality diagnostics, both in hospitals and in the local communities.

\section{IMPLICATIONS FOR CLINICAL PRACTICE}

- Diagnosis of MRSA should be carried out according to specific guidelines.

- Guidelines should be selected and adapted to take account of local resources and needs.

- A coordinated system for quality control should be established to support microbiologic diagnosis, including regional access to central reference facilities.

- Medical and healthcare professionals should be educated in best practice diagnosis.

- Systems should be established to evaluate the implementation of guidelines and best practices across Latin America.

\section{ACKNOWLEDGEMENTS}

\section{Financial support}

Pfizer Inc., New York, NY, USA, provided support for meetings of the Latin American Working Group on Gram Positive Resistance. Pfizer Inc. had no involvement in the collection, analysis and interpretation of data, in the writing of the manuscripts, or in the decision to submit the articles for publication.

\section{Manuscript preparation}

The support provided by Choice Pharma (Hitchin, UK), funded by Pfizer Inc., consisted of manuscript formatting and writing assistance.

\section{DISCLOSURES}

J. Zurita: Advisory Board member and consultant for Pfizer; received research grant from Wyeth.

C. Mejía: Advisory Board member for Pfizer and Abbott; consultant for Pfizer; received funding from Tibotec for HIV research, from Avexa for studies in HIV treatment and from Merck for participation in the SMART study.

M. Guzmán-Blanco: Advisory Board member for Pfizer, Merck and BD; consultant for Pfizer, Wyeth and Janssen; received research funding from Wyeth and Merck.

\section{REFERENCES}

1. Guzmán-Blanco M, Mejía C, Isturiz R et al. Epidemiology of methicillin-resistant Staphylococcus aureus (MRSA) in Latin America. Int J Antimicrob Agents. 2009; 34(4):304-8.

2. Woodford N, Livermore DM. Infections caused by Gram-positive bacteria: a review of the global challenge. J Infect. 2009; 59(1):S4-16.

3. Rodriguez-Noriega E, Seas C, Guzmán-Blanco M et al. Evolution of methicillin-resistant Staphylococcus aureus clones in Latin America. Int J Infect Dis. 2010; 14:e560-e6.

4. CLSI. Performance Standards for Antimicrobial Susceptibility Testing; Nineteenth Informational Supplement (M100-S19). 2009. Clinical and Laboratory Standards Institute. Wayne, PA. (http://www.clsi.org/source/orders/free/m100-s19.pdf) Accessed 23 November 2009.

5. CLSI. Surveillance for Methicillin-Resistant Staphylococcus aureus: Principles, Practices, and Challenges; A Report. CLSI document X07-R. 2010. Clinical and Laboratory Standards Institute, Wayne, PA. (http://www.clsi.org/source/orders/free/ x07-r.pdf) Accessed 7 May 2010.

6. EARSS. New and updated protocols for antimicrobial susceptibility testing of pathogens under EARSS surveillance 2005. (http://www.rivm.nl/earss/Images/Earss\%20manual2005_ tcm61-21261.pdf) Accessed 18 October 2009.

7. Cano ME, Dominguez MA, Baquedano CE et al. Cultivos de vigilancia epidemiologica de bacterias resistentes a los antimicrobianos de interes nosocomial. (http://www.seimc.org/ documentos/protocolos/microbiologia/) Accessed 10 November 2009.

8. Andrews JM. BSAC standardized disc susceptibility testing method (version 7). J Antimicrob Chemother. 2008; 62(2):256-78.

9. Brown DF, Edwards DI, Hawkey PM et al. Guidelines for the laboratory diagnosis and susceptibility testing of methicillinresistant Staphylococcus aureus (MRSA). J Antimicrob Chemother. 2005; 56(6):1000-18.

10. EARSS. Protocols and Guidelines: Technical guide for the detection of Staphylococcus aureus with reduced susceptibility to glycopeptides (VISA/VRSA). (www.earss.rivm.nl) Accessed 6 May 2010.

11. van Griethuysen A, Bes M, Etienne J et al. International multicenter evaluation of latex agglutinates tests for identification of methicillin-resistance Staphylococcus aureus (MRSA). J Clin Microbiol. 2001; 39(1):86-9. 
12. Iorio NL, Ferreira RB, Schuenck RP et al. Simplified and reliable scheme for species-level identification of Staphylococcus clinical isolates. J Clin Microbiol. 2007; 45(8):2564-9.

13. Cauwelier B, Gordts B, Descheemaecker P, Van Landuyt H. Evaluation of a disk diffusion method with cefoxitin (30 microg) for detection of methicillin-resistant Staphylococcus aureus. Eur J Clin Microbiol Infect Dis. 2004; 23(5):389-92.

14. Skov R, Smyth R, Clausen M et al. Evaluation of a cefoxitin 30 microg disc on Iso-Sensitest agar for detection of methicillin-resistant Staphylococcus aureus. J Antimicrob Chemother. 2003; 52(2):204-7.

15. Huang MB, Gay TE, Baker CN et al. Two percent sodium chloride is required for susceptibility testing of staphylococci with oxacillin when using agar-based dilution methods. J Clin Microbiol. 1993; 31(10):2683-8.

16. Novak SM, Hindler J, Bruckner DA. Reliability of two novel methods, Alamar and E test, for detection of methicillin-resistant Staphylococcus aureus. J Clin Microbiol. 1993; 31(11):3056-7.

17. Petersson AC, Miorner H, Kamme C. Identification of mecArelated oxacillin resistance in staphylococci by the E test and the broth microdilution method. J Antimicrob Chemother. 1996; 37(3):445-56.

18. Weller TM, Crook DW, Crow MR et al. Methicillin susceptibility testing of staphylococci by Etest and comparison with agar dilution and mecA detection. J Antimicrob Chemother. 1997; 39(2):251-3.

19. Perry JD, Rennison C, Butterworth LA et al. Evaluation of $S$. aureus ID, a new chromogenic agar medium for detection of Staphylococcus aureus. J Clin Microbiol. 2003; 41(12):5695-8.

20. Hedin G, Fang H. Evaluation of two new chromogenic media, CHROMagar MRSA and S. aureus ID, for identifying Staphylococcus aureus and screening methicillin-resistant S. aureus. J Clin Microbiol. 2005; 43(8):4242-4.

21. Brown DF, Yates VS. Methicillin susceptibility testing of Staphylococcus aureus on media containing five percent sodium chloride. Eur J Clin Microbiol. 1986; 5(6):726-8.

22. Milne LM, Curtis GD, Crow M et al. Comparison of culture media for detecting methicillin resistance in Staphylococcus aureus and coagulase negative staphylococci. J Clin Pathol. 1987; 40(10):1178-81.

23. Annear DI. The effect of temperature on resistance of Staphylococcus aureus to methicillin and some other antibioics. Med J Aust. 1968; 1(11):444-6.

24. Merlino J, Watson J, Rose B et al. Detection and expression of methicillin/oxacillin resistance in multidrug-resistant and nonmultidrug-resistant Staphylococcus aureus in Central Sydney, Australia. J Antimicrob Chemother. 2002; 49(5):793-801.

25. Mouton RP, Mulders SL, de Knijff J, Hermans J. Comparison of test systems for recognition of methicillin resistance in Staphylococcus aureus. Eur J Clin Microbiol Infect Dis. 1989; 8(11):968-73.

26. Felten A, Grandry B, Lagrange PH, Casin I. Evaluation of three techniques for detection of low-level methicillin-resistant Staphylococcus aureus (MRSA): a disk diffusion method with cefoxitin and moxalactam, the Vitek 2 system, and the MRSA-screen latex agglutination test. J Clin Microbiol. 2002; 40(8):2766-71.
27. Mougeot C, Guillaumat-Tailliet J, Libert JM. Staphylococcus aureus: new detection of intrinsic resistance using the diffusion method. Pathol Biol (Paris). 2001; 49(3):199-204.

28. Hiramatsu K, Aritaka N, Hanaki H et al. Dissemination in Japanese hospitals of strains of Staphylococcus aureus heterogeneously resistant to vancomycin. Lancet. 1997; 350(9092):1670-3

29. Oliveira GA, Dell'Aquila AM, Masiero RL et al. Isolation in Brazil of nosocomial Staphylococcus aureus with reduced susceptibility to vancomycin. Infect Control Hosp Epidemiol. 2001; 22(7):443-8.

30. Picao R, Sader H, Jones R et al. Analysis of resistance and vancomycin 'reverse creep' in Latin America Staphylococcus aureus: ten-year report of the SENTRY Antimicrobial Surveillance Program (1997-2006). Clin Microbiol Infect. 2008; 14:S173.

31. CDC. Vancomycin-resistant Staphylococcus aureus. Morb Mortal Wkly Rep. 2004; 53:322-4.

32. Tenover FC, Weigel LM, Appelbaum PC et al. Vancomycinresistant Staphylococcus aureus isolate from a patient in Pennsylvania. Antimicrob Agents Chemother. 2004; 48(1):275-80.

33. Sakoulas G, Moise-Broder PA, Schentag J et al. Relationship of MIC and bactericidal activity to efficacy of vancomycin for treatment of methicillin-resistant Staphylococcus aureus bacteremia. J Clin Microbiol. 2004; 42(6):2398-402.

34. Yusof A, Engelhardt A, Karlsson A et al. Evaluation of a new Etest vancomycin-teicoplanin strip for detection of glycopeptide-intermediate Staphylococcus aureus (GISA), in particular, heterogeneous GISA. J Clin Microbiol. 2008; 46(9):3042-7.

35. Wootton M, MacGowan AP, Walsh TR, Howe RA. A multicenter study evaluating the current strategies for isolating Staphylococcus aureus strains with reduced susceptibility to glycopeptides. J Clin Microbiol. 2007; 45(2):329-32.

36. Hiramatsu K, Hanaki H, Ino T et al. Methicillin-resistant Staphylococcus aureus clinical strain with reduced vancomycin susceptibility. J Antimicrob Chemother. 1997; 40(1):135-6.

37. Marchese A, Balistreri G, Tonoli E et al. Heterogeneous vancomycin resistance in methicillin-resistant Staphylococcus aureus strains isolated in a large Italian hospital. J Clin Microbiol. 2000; 38(2):866-9.

38. Ariza J, Pujol M, Cabo J et al. Vancomycin in surgical infections due to methicillin-resistant Staphylococcus aureus with heterogeneous resistance to vancomycin. Lancet. 1999; 353(9164):1587-8.

39. Reyes J, Rincon S, Diaz L et al. Dissemination of methicillinresistant Staphylococcus aureus USA300 sequence type 8 lineage in Latin America. Clin Infect Dis. 2009; 49(12):1861-7.

40. Howe RA, Wootton M, Walsh TR et al. Expression and detection of hetero-vancomycin resistance in Staphylococcus aureus. J Antimicrob Chemother. 1999; 44(5):675-8.

41. Boyle-Vavra S, Berke SK, Lee JC, Daum RS. Reversion of the glycopeptide resistance phenotype in Staphylococcus aureus clinical isolates. Antimicrob Agents Chemother. 2000; 44(2):272-7. 